\title{
Electroreductive Synthesis of Polysilanes with Ordered Sequences
}

\author{
Manabu Ishifune
}

Additional information is available at the end of the chapter

http://dx.doi.org/10.5772/46243

\section{Introduction}

Polysilanes (Scheme 1) [1] have attracted considerable attention due to their usefulness as the precursors for thermally stable ceramics [2,3] or a material for microlithography $[4,5]$, and also due to their potentiality in the preparation of new types of material showing semiconducting, photoconducting, or nonlinear optical property [6-8].

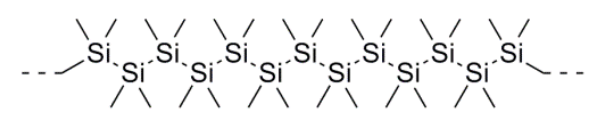

\section{Scheme 1.}

In contrast to the growing interest with the polysilane, the method of preparation hitherto known is highly limited. So far, the almost only practical method is the condensation of organodichlorosilane with alkali metal (Wurtz type condensation). This method, however, requires drastic reaction conditions and hence, is very much limited in the type of substituent that is allowed to be located on the monomer. Although several modified or alternative methods such as sonochemical coupling of dichlorosilane promoted by alkali metal [9-11], transition metal catalyzed reaction of hydrosilane [12, 13], anionic polymerization of masked disilene [14, 15], and ring opening polymerization of cyclic organosilane [16, 17] have been proposed, they are not always extensively effective as preparative methods.

The electroreductive coupling of dichlorosilanes with mercury electrode has been reported by Hengge in 1976 as a method to form disilanes [18], though this method was not effective in the preparation of polysilanes $[19,20]$.

On the other hand, we have recently found that the electroreduction of organic compounds with $\mathrm{Mg}$ electrode promotes a variety of unique reactions which can not be attained without 
using the Mg electrode. The use of $\mathrm{Mg}$ electrodes was highly effective to the formation of SiSi bond and the synthesis of high molecular weight polysilanes [21, 22].

In this chapter, we describe the details of the electroreductive synthesis of high molecular weight polysilane and some types of functionalized polysilanes and also polygermanes, including the additional information about the effects of electrode material and monomer concentration. We also demonstrate that our electroreduction system is successfully applied for the synthesis of the sequence-ordered oligosilanes and polysilanes.

\section{Formation of $\mathrm{Si}-\mathrm{Si}$ bonds by electroreductive coupling of chlorosilanes}

\section{$[21,22]$}

The electroreduction of chlorodimethylphenylsilane (1a) was studied as the model reaction (Scheme 2) and carried out under a variety of reaction conditions. In the first place, the cathodic reduction was performed in a divided cell since Si-Si bond is electrochemically oxidized at the potential range $0.7-1.6 \mathrm{~V}$ vs. SCE. The yield of 1,1,2,2-tetramethyl-1,2diphenyldisilane (2a) was, however, unexpectedly low under this reaction conditions. In the next place, the idea of using a sacrificial electrode was studied in order to avoid the undesirable anodic oxidation of Si-Si bond in an undivided cell and it was found that the electroreduction of $1 \mathrm{a}$ with $\mathrm{Mg}$ electrode was highly effective for the formation of Si-Si bond and $2 \mathbf{a}$ was obtained in an excellent yield.

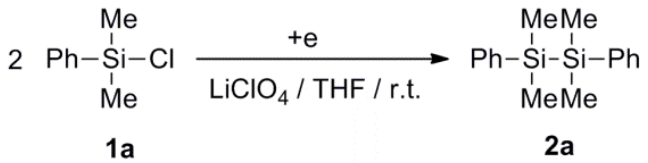

Scheme 2.

The material of electrode is one of the most important factors to control the formation of SiSi bond (Table 1). When a solution of 1a in dry THF containing $\mathrm{LiClO}_{4}$ as a supporting electrolyte was electrochemically reduced with $\mathrm{Mg}$ cathode and anode with a constant current (current density $=30 \mathrm{~mA} / \mathrm{cm}^{2}$, supplied electricity $=2.0 \mathrm{~F} / \mathrm{mol}$ ), the coupling product 2a was obtained in $92 \%$ isolated yield (entry 1). The results that $\mathrm{Pt}$, carbon, or $\mathrm{Zn}$ is not effective electrode in the formation of Si-Si bond (entries 2-4) clearly indicate that $\mathrm{Mg}$ plays some important roles in the formation of $\mathrm{Si}-\mathrm{Si}$ bond. Although details of the role of $\mathrm{Mg}$ in the mechanism of formation of $\mathrm{Si}-\mathrm{Si}$ bond is not always clear at present, the unique reactivity of $\mathrm{Mg}$ electrode is undoubtedly shown in this reaction.

The cathodic coupling of other organochlorosilanes was carried out under the optimized reaction condition, that is, $\mathrm{Mg}$ cathode and anode were alternated with the interval of 1 min., supporting electrolyte was $\mathrm{LiClO}_{4}$, solvent was THF, and the electricity passed was 2.0 F/mol (Scheme 3). The results summarized in Table 2 show the high potentiality of this method in the synthesis of a variety of disilanes. Moreover, it is remarkable that the extent of contamination with siloxane (Si-O-Si) was less than $2 \%$. 


\begin{tabular}{ccccc}
\hline entry & anode & cathode & alternation $^{b}$ & yield of $\mathbf{2 a}, \%^{c}$ \\
\hline 1 & $\mathrm{Mg}$ & $\mathrm{Mg}$ & yes & 92 \\
2 & $\mathrm{Pt}$ & $\mathrm{Pt}$ & yes & 0 \\
3 & $\mathrm{C}$ & $\mathrm{C}$ & yes & 0 \\
4 & $\mathrm{Zn}$ & $\mathrm{Zn}$ & yes & trace \\
5 & $\mathrm{Pt}$ & $\mathrm{Mg}$ & no & 0 \\
6 & $\mathrm{Mg}$ & $\mathrm{Pt}$ & no & $93^{d}$ \\
\hline
\end{tabular}

${ }^{a}$ The electroreduction was carried out under the constant current conditions (current density $=30 \mathrm{~mA} / \mathrm{cm}^{2}$, supplied electricity $=2.0 \mathrm{~F} / \mathrm{mol}$ ). ${ }^{b}$ The anode and cathode were alternated with an interval of $1 \mathrm{~min}$. ${ }^{c}$ Material yield based on 1 a. dUltrasound $(47 \mathrm{kHz})$ was applied during the reaction.

Table 1. Effect of electrode materials in the electroreductive formation of 1,1,2,2-tetramethyl-1,2diphenyldisilane (2a) ${ }^{a}$

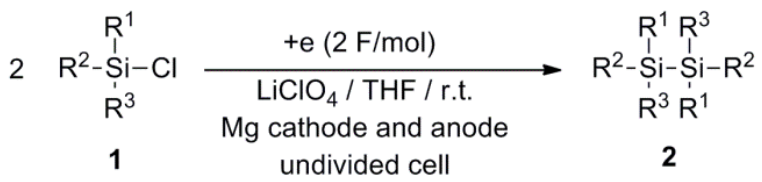

Scheme 3.

\begin{tabular}{ccccccc}
\hline \multirow{2}{*}{ entry } & \multicolumn{3}{c}{ chlorosilanes $\mathbf{1}$} & \multicolumn{3}{c}{ yield of 2, \% ${ }^{a}$} \\
\cline { 2 - 5 } & & $\mathrm{R}^{1}$ & $\mathrm{R}^{2}$ & $\mathrm{R}^{3}$ & & $\mathbf{2 b}$ \\
\hline 1 & $\mathbf{1 b}$ & $\mathrm{Me}$ & $\mathrm{Me}$ & $\mathrm{Me}$ & & $\mathbf{2 b}$ \\
2 & $\mathbf{1 c}$ & $\mathrm{Me}$ & $\mathrm{Ph}$ & $\mathrm{Ph}$ & $\mathbf{2 c}$ & 77 \\
3 & $\mathbf{1 d}$ & $\mathrm{Ph}$ & $\mathrm{Ph}$ & $\mathrm{Ph}$ & $\mathbf{2 d}$ & 85 \\
\hline
\end{tabular}

${ }^{a}$ Isolated yield based on $\mathbf{1}$.

Table 2. Electroreductive synthesis of disilanes 2

Two types of mechanism may be proposed to this electroreductive Si-Si bond forming reaction. The first prosible mechanism is a radical coupling in which a silyl radical formed by one electron reduction of the starting chlorosilane couples with another silyl radical to give the disilane. In the second mechanism, two-electron reduction of the chlorosilane yields an active species equivalent to silyl anion which reacts with chlorosilane to give a dimer. In order to have an insight into the mechanism, the products obtained in the mixed system of chlorotrimethylsilane (1b) and chlorotriphenylsilane (1d) (1) : $\mathbf{1 d}=1: 1)$ were studied in detail (Scheme 4). The resulting products were 1:1 mixture of the mixed coupling product (2e) and the homocoupling product of $\mathbf{1 d}$ (hexaphenyldisilane (2d)), whereas the homocoupling product of $1 \mathbf{b}$, hexamethyldisilane $(\mathbf{2 b})$ was not found in the products at all. This result seems to agree with the anionic mechanism. That is, $\mathbf{1 d}$ is first reduced to triphenylsilyl anion that reacts with $\mathbf{1 b}$ and $\mathbf{1 d}$ to afford disilanes $\mathbf{2 e}$ and $\mathbf{2 d}$ respectively. The electrophilicity of chlorosilanes $\mathbf{1 b}$ and $\mathbf{1 d}$ are high enough to be attacked equally by the triphenylsilyl anion at the half conversion (supplied electricity $=1 \mathrm{~F} / \mathrm{mol}$ based on the total amount of $\mathbf{1 b}$ and $\mathbf{1 d}$ ). In the radical mechanism, however, if only $\mathbf{1 d}$ is reduced to yield a radical, the formation of $\mathbf{2} \mathbf{e}$ is not reasonable, whereas if two types of radical are formed by 
the reduction of both $\mathbf{1 b}$ and $\mathbf{1 d}$, the absence of $\mathbf{2 b}$ in the products is unreasonable. Thus, the anionic mechanism is the most reasonable in this coupling reaction. The fact that the reduction potential of $\mathbf{1 d}$ is much more positive than that of $1 \mathrm{~b}$ also supports the above mentioned reaction mechanism.

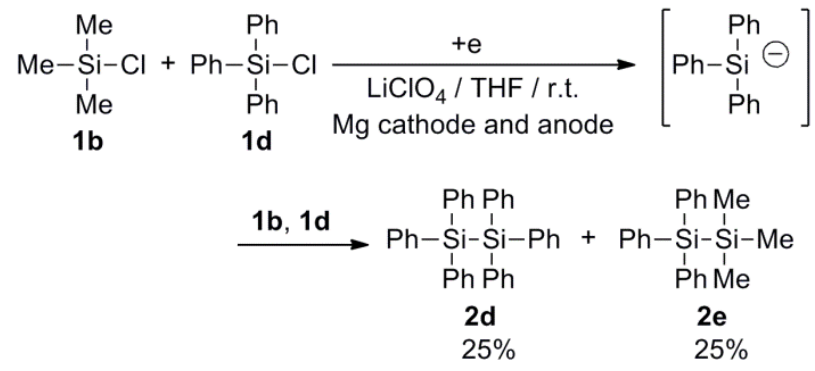

\section{Scheme 4.}

\section{Stepwise synthesis of oligosilanes $[22,23]$}

This method is also applicable to the synthesis of trisilanes and tetrasilanes. For example, the electroreductive cross coupling of organodichlorosilanes (3) with chlorotrimethylsilane (1) (5 equivalent to 3 ) gave the corresponding trisilanes 4 in moderate to good material yields (Scheme 5) and that of 1,2-dichloro-1,1,2-trimethyl-2-phenyldisilane (5) and $\mathbf{1 b}$ (5 equivalent to 5 ) gave tetrasilane 6 in 55\% yield (Scheme 6). Trisilane $4 \mathrm{c}$ is a key intermediate for the photochemical synthesis of tetramesityldisilene which is known as an isolable disilene.

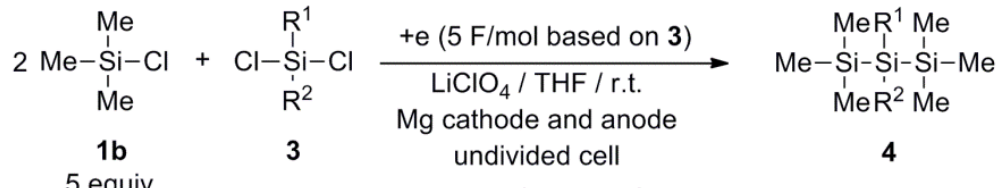

$$
\begin{aligned}
& 3 / 4 \text { a; } R^{1}=M e, R^{2}=P h \quad 59 \% \\
& \text { b; } \mathrm{R}^{1}=\mathrm{R}^{2}=\mathrm{Ph} \quad 73 \% \\
& \text { c; } R^{1}=R^{2}=\text { Mesityl } \quad 92 \% \\
& \text { d; } R^{1}=P h, R^{2}={ }_{72}{ }_{71 \%}
\end{aligned}
$$

Scheme 5

Scheme 5.

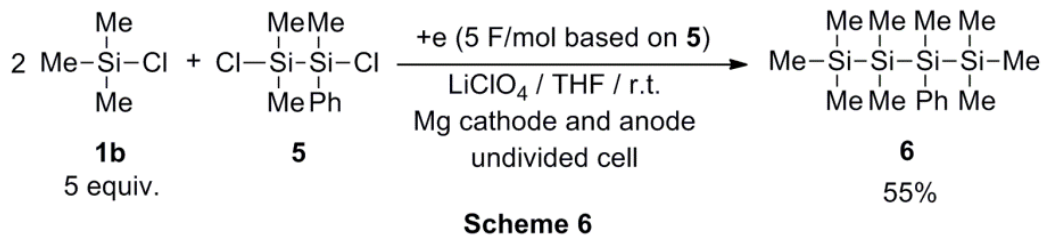

Scheme 6. 
The mildness of the reaction conditions of this electroreductive method is favorable for the synthesis of oligosilanes having various functionalities such as $\mathrm{Si}-\mathrm{H}$ bonds which are known to be reactive under radical or anionic condition. The electroreductive cross-coupling reaction of chlorodimethylsilane (7) with dichlorodiphenylsilane (3b), in fact, gave the corresponding trisilane 8 (Scheme 7). The Si-H bond was readily transformed to the Si-Cl bond by the treatment with catalytic amount of benzoylperoxide in carbontetrachloride. Using this method 1,3-dihydro-1,1,3,3-tetramethyl-2,2-diphenyltrisilane (8) was transformed to the corresponding chloride 9 (Scheme 7). The further electroreduction of 1,3-dichloro1,1,3,3-tetramethyl-2,2-diphenyltrisilane (9) with chlorodimethylsilane (7) gave the corresponding pentasilane 10 (Scheme 8), and these sequences were utilized for the synthesis of the odd-numbered oligosilanes. In the same manner, the even-numbered oligosilanes can be prepared. For instance, 1,4-dichloro-1,1,2,3,3,4,4-heptamethyl-2phenyltetrasilane (11) can be prepared by the reaction between 7 and 1,2-dichloro-1,1,2trimethyl-1-phenyldisilane (5) (Scheme 9). Accordingly, the electroreductive cross-coupling reactions followed by the chlorination provided a powerful method for the stepwise elongation of Si-Si bonds and synthesis of sequence-controlled oligosilanes.

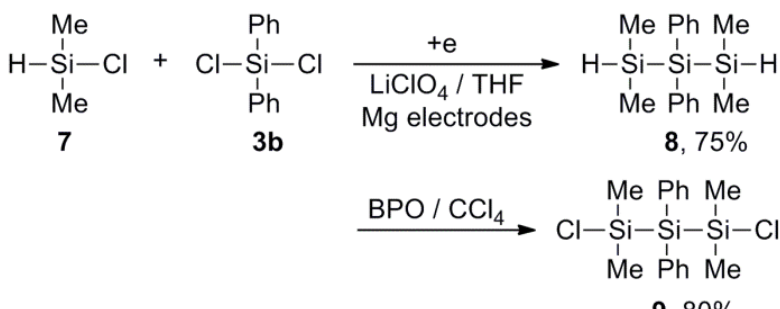

$9,80 \%$

Scheme 7.

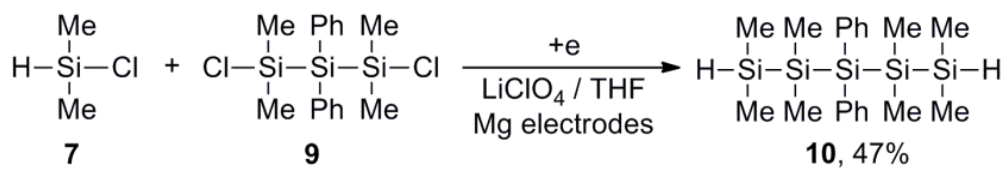

Scheme 8.

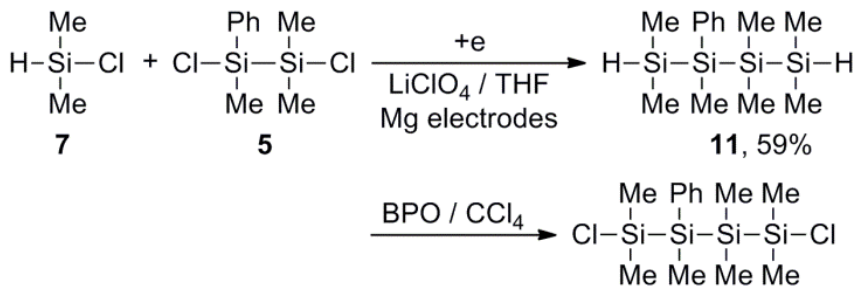

$12,70 \%$

\section{Scheme 9.}




\section{Electroreductive polymerization of dichloromethylphenylsilane [22]}

Electroreduction of dichloromethylphenylsilane (3a) (Scheme 10) carried out under the above mentioned reaction conditions gave polymethylphenylsilane (13) in low yield (Table 3, entries 1, 2). The sonication of ultrasound was found to be necessary for the electroreductive polymerization of $\mathbf{3 a}$ (entry 3). The low yield of $\mathbf{1 3}$ may be explained by the difficulty of keeping the electric current in a suitable level due to the increase of the terminal voltage with progress of the reaction. This difficulty was overcome by the alternation of anode and cathode with a suitable interval (15 sec., Table 3, entry 4 ) and the material yield of $\mathbf{1 3}$ was remarkably improved.

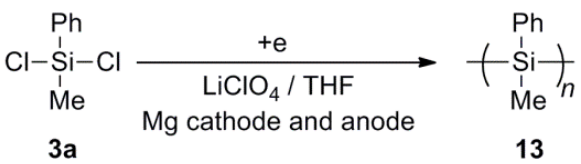

Scheme 10.

\begin{tabular}{cccccc}
\hline entry & alternation $^{c}$ & sonication $^{d}$ & $M^{e}$ & $M w / M^{e}$ & yield of 13, \%f,g \\
\hline 1 & no & no & - & - & - \\
2 & yes & no & 4000 & 1.4 & 7 \\
3 & no & yes & 3900 & 1.4 & 17 \\
4 & yes & yes & 5200 & 1.5 & 43 \\
\hline
\end{tabular}

${ }^{a}$ Concentration of monomer $3 \mathrm{a}$ is $0.33 \mathrm{~mol} / \mathrm{L}$. ${ }^{b}$ Supplied electricity is $4 \mathrm{~F} / \mathrm{mol}$. ${ }^{c}$ The anode and cathode were alternated with an interval of $15 \mathrm{sec}$. ${ }^{\text {TT }}$ The ultrasound $(47 \mathrm{kHz})$ was applied during the electroreduction. ${ }^{e}$ Determined by GPC based on polystyrene standard. $f$ Purified by reprecipitation from benzene-EtOH. 8 Material yield based on $3 a$.

Table 3. Electroreductive synthesis of poly(methylphenylsilane) (13)a,b

$\mathrm{Mg}$ is a remarkably effective material of electrode also for the formation of $\mathbf{1 3}$ (Table 4), whereas $\mathrm{Al}$ gave low yield (entry 4) and other materials such as $\mathrm{Cu}$ and $\mathrm{Ni}$ were rather ineffective (entries 2,3). The electroreduction systems using $\mathrm{Al}$ or $\mathrm{Cu}$ anode in other electrolytes (Al anode/Bu $4 \mathrm{NCl} / \mathrm{DME}$ [24], $\mathrm{Al}$ anode/LiCl/THF-HMPT [25], or $\mathrm{Cu} / \mathrm{Bu}_{4} \mathrm{NClO}_{4} / \mathrm{DME}$ [26]) have been also reported, however, the molecular weight of the resulting polysilanes is relatively low. Other than Mg electrodes, the use of $\mathrm{Ag}$ anode and Pt cathode in DME containing Bu4NCLO 4 is also reported to be effective to obtain high molecular weight polysilane [27, 28].

\begin{tabular}{ccccc}
\hline entry & electrode materials & $\mathrm{Mn}^{b}$ & $\mathrm{Mw} / \mathrm{Mn}^{b}$ & yield of 13, \%c,d \\
\hline 1 & $\mathrm{Mg}$ & 5200 & 1.5 & 43 \\
2 & $\mathrm{Cu}$ & 700 & 1.1 & $-e$ \\
3 & $\mathrm{Ni}$ & 640 & 1.1 & $-e$ \\
4 & $\mathrm{Al}$ & 4700 & 1.5 & 15 \\
\hline
\end{tabular}

${ }^{a}$ Conditions: $[$ monomer $3 \mathrm{a}]=0.33 \mathrm{~mol} / \mathrm{L}$; supplied electricity $=4 \mathrm{~F} / \mathrm{mol}$; The ultrasound $(47 \mathrm{kHz})$ was applied during the electroreduction. The anode and cathode were alternated with an interval of $15 \mathrm{sec} .{ }^{b}$ Determined by GPC based on polystyrene standard. ${ }^{c}$ Purified by reprecipitation from benzene-EtOH. ${ }^{d}$ Material yield based on $3 a .{ }^{e}$ No precipitate was obtained after usual reprecipitation procedure.

Table 4. Effect of electrode materials in the electroreductive synthesis of poly(methylphenylsilane) (13) 
The effect of monomer concentration was investigated in order to obtain high molecular weight polysilane (Table 5). The molecular weight of $\mathbf{1 3}$ becomes higher with the increase in the concentration of $\mathbf{3 a}$. The molecular weight $(\mathrm{Mn})$ of $\mathbf{1 3}$ was, for instance, 31,000 when the electroreduction of $\mathbf{3 a}$ was carried out under high concentration condition $(1.2 \mathrm{~mol} / \mathrm{L})$ at 0.5 $\mathrm{F} / \mathrm{mol}$ of supplied electricity though the material yield of $\mathbf{1 3}$ decreased.

The most satisfactory result, in which material yield was $79 \%$ and molecular weight $(\mathrm{Mn})$ was 9900, was obtained when the concentration of 3a was $0.67 \mathrm{~mol} / \mathrm{L}$ (entry 2). The polysilane 13 obtained here showed relatively sharp monomodal distribution of molecular weight in the elution profile of GPC, whereas the polysilanes prepared by the alkali metal condensation method usually showed broad bimodal distribution.

\begin{tabular}{cccccc}
\hline entry & $\begin{array}{c}\text { monomer 3a, } \\
\text { mol/L }\end{array}$ & $\begin{array}{c}\text { supplied electricity, } \\
\text { F/mol }\end{array}$ & $M^{b}$ & $M w / \mathrm{Mn}^{b}$ & $\begin{array}{c}\text { yield of 13, } \\
\%^{c, d}\end{array}$ \\
\hline 1 & 0.33 & 4.0 & 5200 & 1.5 & 43 \\
2 & 0.67 & 4.0 & 9900 & 2.1 & 79 \\
3 & 2.5 & 2.2 & 18000 & 2.1 & 43 \\
4 & 6.3 & 0.8 & 19000 & 2.8 & 15 \\
5 & 12 & 0.5 & 31000 & 1.8 & 8 \\
\hline
\end{tabular}

${ }^{a}$ The electroreduction was carried out by using Mg electrodes under sonication of ultrasound $(47 \mathrm{kHz})$. The anode and cathode were alternated with an interval of $15 \mathrm{sec} .{ }^{b}$ Determined by GPC based on polystyrene standard. ${ }^{c}$ Purified by reprecipitation from benzene-EtOH. ${ }^{\circledR}$ Material yield based on $\mathbf{3 a}$.

Table 5. Effect of monomer concentration in the electroreductive synthesis of 13a

The mechanism of electroreductive formation of polysilane is not always perfectly clear, though the initial step of reaction is obviously the reduction of $\mathbf{3 a}$ to a silyl anion species $\mathbf{1 4}$. Two types of reaction patterns may be proposable to the propagation step. In the first case, the reaction of $\mathbf{1 4}$ with $\mathbf{3 a}$ gives a dimer that yields trimer, tetramer, and finally polymer upon repeated reaction with 14 (Scheme 11). In another pattern of the propagation, the oligomers such as dimer, trimer, and the like $\mathbf{1 5}$ are reduced to give the oligomeric active species, which then react with oligomer $\mathbf{1 5}$ or $\mathbf{3 a}$ to give finally polymer. (Scheme 12). Although it is not always possible to specify the extent of contribution of each pattern to the propagation step, the former reaction probably proceeds mainly, since the electrochemical reduction of oligomeric silyl chloride $\mathbf{1 5}$ may be rather difficult when it is analogized with the electroreduction of long chain alkyl chlorides.
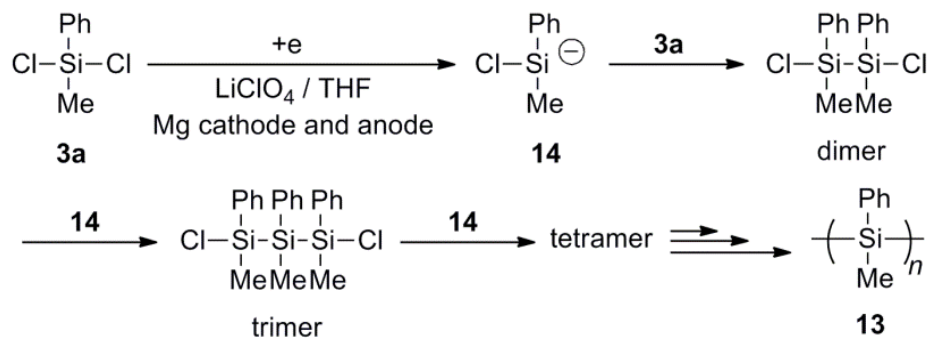

Scheme 11. 


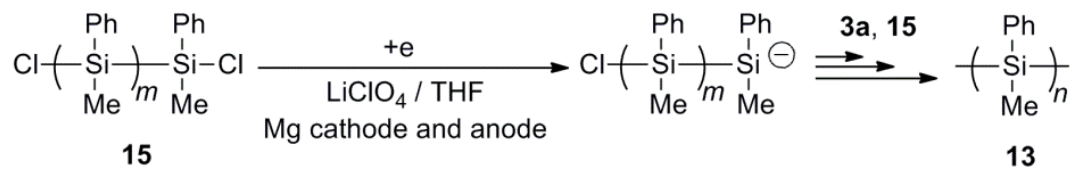

Scheme 12.

\section{Electroreductive synthesis of functionalized polysilanes [29]}

The mildness of the polymerization conditions of the electroreductive method is favorable for the synthesis of the polysilanes having a variety of hydroxyl-related functional groups. The electroreduction of a mixture of $\mathbf{3 a}$ and the dichlorosilanes having protected hydoxyphenyl groups (3d-g) with $\mathrm{Mg}$ electrode afforded the corresponding copolymers 16 (16d-g, Scheme 13), and the deprotection of the resulting copolymers gave the polysilanes having hydroxyl groups. The reactivity of $3 \mathbf{d}-\mathbf{g}$ highly depends on the type of protecting group (Table 6). Homopolymerization of $\mathbf{3 g}$, for example, gave $\mathbf{1 6 g}$ (entry 10), whereas other monomers did not afford polymers but oligomeric compounds (entries 3, 5, 8).

The modification or the property of polysilane must be achieved by using the hydroxyl group located on the polymer $\mathbf{1 6 d}$ as a key functional group. The deprotection of the methoxymethyl group of $\mathbf{1 6 d}$ (Table $\mathbf{6}$, entry 1 ) with $10 \% \mathrm{HCl}$ aqueous solution followed by the reaction with hexamethylene diisocyanate resulted in a remarkable increase in the molecular weight with indicating the linkage of the polymer chain (Scheme 14).
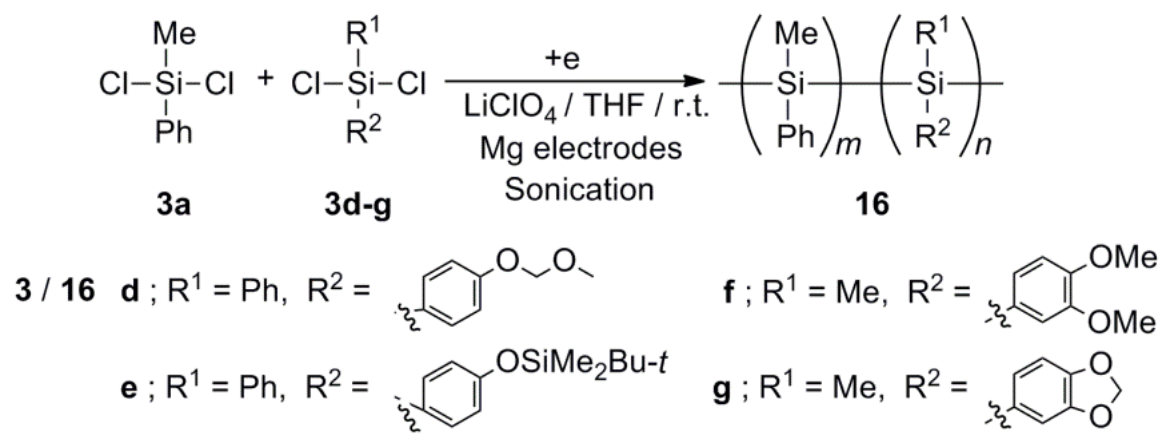

Scheme 13. 


\begin{tabular}{ccccc}
\hline entry & charged $\mathbf{m o l} \%$ of $\mathbf{3 d}-\mathbf{g}^{\mathrm{b}}$ & yield of $\mathbf{1 6}, \%$ c, d & $\mathrm{Mn}^{\mathrm{e}}$ & $\mathrm{Mw} / \mathrm{Mn}^{\mathrm{e}}$ \\
\hline 1 & $7(\mathbf{3 d})$ & $79(7)$ & 9900 & 1.9 \\
2 & $10(\mathbf{3 d})$ & $57(12)$ & 6900 & 1.7 \\
3 & $100(\mathbf{3 d})$ & $28(100)$ & 1100 & 1.2 \\
4 & $10(\mathbf{3 e})$ & $36(11)$ & 6100 & 1.5 \\
5 & $100(\mathbf{3 e})$ & $-\mathrm{f}(100)$ & 1100 & 1.2 \\
6 & $10(\mathbf{3 f})$ & $50(6)$ & 4500 & 1.3 \\
7 & $50(\mathbf{3 f})$ & $22(46)$ & 4600 & 1.3 \\
8 & $100(\mathbf{3 f})$ & $-\mathrm{f}(100)$ & 1700 & 1.3 \\
9 & $10(\mathbf{3 g})$ & $56(17)$ & 4600 & 1.3 \\
10 & $100(\mathbf{3 g})$ & $57(100)$ & 4000 & 1.1 \\
\hline
\end{tabular}

${ }^{a}$ The electroreduction was carried out by using $\mathrm{Mg}$ electrodes under sonocation $(47 \mathrm{kHz})$, and the anode and cathode were alternated with an interval of $15 \mathrm{sec}$. Total monomer concentration, $0.67 \mathrm{~mol} / \mathrm{L}$; supplied electricity, $4 \mathrm{~F} / \mathrm{mol} .{ }^{b} \mathbf{3 d}-$ g/(3d-g+3a) x 100. cPurified by reprecipitaion from benzene-EtOH. ${ }^{\text {TT }}$ The values in parentheses indicate the mol\% of $3 \mathbf{d}-$ $\mathrm{g}$ units in the resulting copolymers determined by $1 \mathrm{H}$ NMR. ${ }^{e}$ Determined by GPC based on polystyrene standard. fPolymer was not obtained by reprecipitation.

Table 6. Electroreductive synthesis of functionalized polysilanes ${ }^{a}$

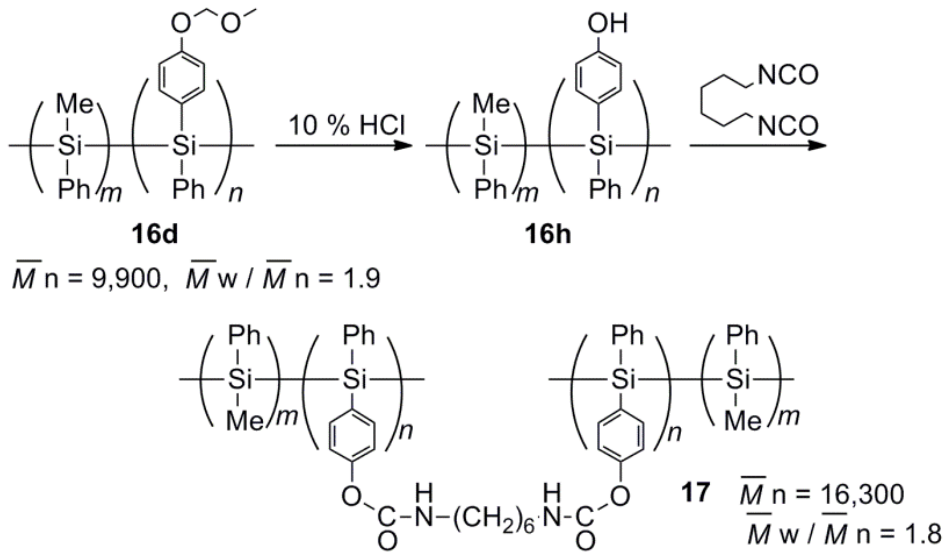

Scheme 14.

\section{Electroreductive Polymerization of Dichlorooligosilanes [23]}

The electroreductive polymerization of the dichlorooligosilanes is highly promising for the synthesis of sequence-ordered polysilanes. The electroreduction of dicholodisilane 5 was found to give the corresponding polysilane 18 consisting of disilane units (Scheme 15). The electroreductive polymerization was carried out under a variety of reaction conditions, however, the yield of the resulting polymer was very low (Table 7). It is probably due to high reactivity of the disilene intermediate formed by the electroreduction of 5 . In fact, the addition of naphthalene, which could make a masked disilene intermediate, into the reaction system slightly increased the yield of the polysilane 18 (entry 6). 


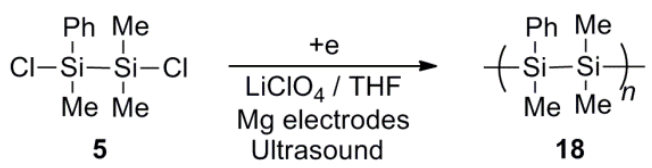

Scheme 15.

\begin{tabular}{cccccc}
\hline \multirow{2}{*}{ entry } & \multirow{2}{*}{ dichlorosilane 5, mol/L } & supplied electricity, F/mol & \multicolumn{3}{c}{ polysilane 18 } \\
\cline { 4 - 6 } & & & $M^{b}$ & $M w / \mathrm{Mn}^{b}$ & yield, \% \\
\hline 1 & 0.11 & 4 & 2900 & 2.7 & 2.7 \\
2 & 0.33 & 4 & 3600 & 2.3 & 2.7 \\
3 & 0.67 & 2 & 2100 & 2.9 & 1.0 \\
4 & 0.33 & 6 & 2800 & 2.7 & 3.9 \\
5 & 0.33 & 4 & 3000 & 3.0 & 1.0 \\
$6^{c}$ & 0.33 & 2500 & 1.8 & 13.0 \\
\hline
\end{tabular}

${ }^{a}$ The electroreduction was carried out by using $\mathrm{Mg}$ electrodes under sonocation $(47 \mathrm{kHz})$, and the anode and cathode were alternated with an interval of $15 \mathrm{sec}$. Total monomer concentration, $0.67 \mathrm{~mol} / \mathrm{L}$; supplied electricity, $4 \mathrm{~F} / \mathrm{mol}$. ${ }^{b}$ Determined by GPC based on polystyrene standard. ${ }^{c}$ The electroreduction was carried out in the presence of naphthalene.

Table 7. Electroreduction polymerization of dichlorosilane $5^{a}$

Dichlorooligosilanes, such as dichlorotrisilane 9 was found to be good monomers for the electroreductive synthesis of the polysilanes having longer sequence units (Schemes 16). The temperature control is found to be very important in the electroreductive polymerization of 9 (Table 8). The reaction at higher temperature, the backbiting reaction of the propagating polymer proceeded forming cyclohexasilane as a by-product (entry 1). This side reaction was successfully suppressed when the reaction was carried out below $0{ }^{\circ} \mathrm{C}$, and polysilanes 19 having relatively high molecular weight were obtained (entries 3,4). In the optimized reaction conditions, the electroreduction of dichlorotetrasilane 12 gave the corresponding polysilane 20, units of which were ordered in four sequences in satisfactory yield (Scheme 17). The polymerizability of dichlorooligosilanes under the electroreduction conditions seems to be mainly affected by the substituents on the chlorinated terminal silicon atom, and this fact provides a wide possibility to design the oligosilane sequences of the inner silicon atoms.

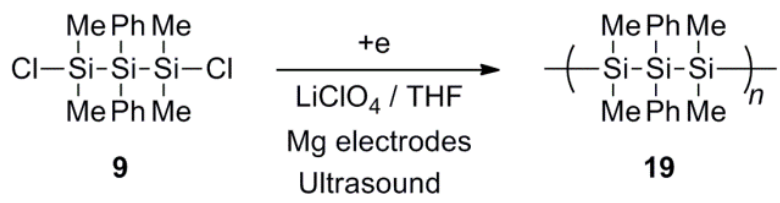

\section{Scheme 16.}




\begin{tabular}{ccccc}
\hline entry & polymerization temperature, ${ }^{\circ} \mathrm{C}$ & $\mathrm{Mn}^{b}$ & $\mathrm{Mw} / \mathrm{Mn}^{b}$ & yield of $\mathbf{1 9}, \%^{c}$ \\
\hline 1 & 18 & 3800 & 1.44 & $(42)^{d}$ \\
2 & 0 & 4700 & 1.87 & 50 \\
3 & -10 & 5500 & 1.54 & 35 \\
4 & -15 & 4400 & 1.42 & 16 \\
\hline
\end{tabular}

${ }^{a}$ The electroreduction was carried out by using $\mathrm{Mg}$ electrodes under sonocation $(47 \mathrm{kHz})$, and the anode and cathode were alternated with an interval of $15 \mathrm{sec}$. [Dichlorosilane 9] $=0.27 \mathrm{~mol} / \mathrm{L} ;\left[\mathrm{LiClO}_{4}\right]=0.35 \mathrm{~mol} / \mathrm{L}$; supplied electricity $=4$ $\mathrm{F} / \mathrm{mol} .{ }^{b}$ Determined by GPC based on polystyrene standard. ${ }^{c}$ Purified by reprecipitation from benzene-EtOH. dContaminated by 1,1,2,2,4,4,5,5-octamethyl-3,3,6,6-tetraphenylcylcohexasilane.

Table 8. Electroreductive polymerization of dichlorosilane $\mathbf{9}^{a}$

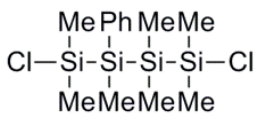

12

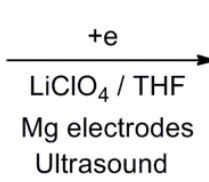

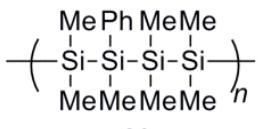

20

$$
\text { Yield, } 40 \% \quad \begin{aligned}
& \bar{M} \mathrm{n}=3200 \\
& \bar{M} \mathrm{w} / \bar{M} \mathrm{n}=1.30
\end{aligned}
$$

Scheme 17.

\section{Electroreductive polymerization of dichlorosilanes in the presence of disilane additives [30]}

The disilane additives, which are generated in situ in electroreductive coupling of the corresponding chlorosilanes, were found to be effective to the promotion of the electroreductive polymerization of dichloromethylphenylsilane (3a) and the control of the molecular weight distribution of the resulting polysilanes (Scheme 18, Table 9). The electroreduction of dichlorosilane $3 \mathbf{a}$ in the presence of 1,1,1-trimethyl-2,2,2triphenyldisilane gives the corresponding polysilane 13 in $56 \%$ yield, and the number average molecular weight and the molecular weight distribution are determined by GPC to be 3000, and 1.10 respectively (Table 9, entry 3). The reduction of dichloromethylphenylsilane (3a) by Wurtz type condensation using metal lithium in the presence of catalytic amount 1,1,1-trimethyl-2,2,2-triphenyldisilane affords five- and sixmembers ring products [31]. On the other hand, the cyclosilanes are not detected under the electroreductive conditions. The use of 1,1,12,2,2-hexaphenyldisilane affords the polysilane 13 in $59 \%$ yield, and the $M w / M n$ is 1.08 (entry 4). Thus, the polysilanes prepared in the presence of the disilane additive containing triphenylsilyl group show narrower molecular weight distributions than the polysilane prepared without the disilane additive.

The mechanism for the triphenylsilyl substituted disilane to control the electroreductive polymerization suggested is as follows (Scheme 19). The electroreductively generated reactive silyl anion species at the terminus of the propagating polymer is trapped with the disilane forming a relatively stable triphenylsilyl anion and inhibits the undesirable side reactions such as backbiting reaction. The triphenylsilyl anion attacks as a nucleophile to the chlorinated silicon atom at the terminal of the propagating polymer to give the 


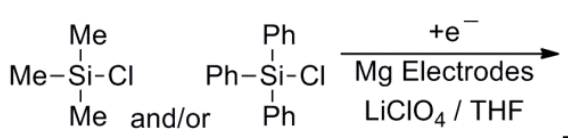

$\begin{array}{ll}R^{1} & -S i-R \\ R^{1} & R^{2}\end{array}$

$$
\begin{aligned}
& \text { Disilane Additives } \\
& \mathrm{R}^{1}, \mathrm{R}^{2}=\mathrm{Me} \\
& \mathrm{R}^{1}=\mathrm{Me}, \mathrm{R}^{2}=\mathrm{Ph} \\
& \mathrm{R}^{1}, \mathrm{R}^{2}=\mathrm{Ph}
\end{aligned}
$$

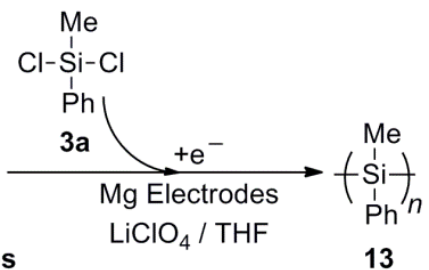

13

Scheme 18.

\begin{tabular}{ccccc}
\hline entry & disilane additives $^{b}$ & $M^{c}$ & $M w / M^{c}$ & yield of $\mathbf{2 a}, \%^{d}$ \\
\hline 1 & - & 3200 & 1.65 & 38 \\
2 & $\mathrm{Me}_{3} \mathrm{SiSiMe}_{3}$ & 3700 & 1.39 & 54 \\
3 & $\mathrm{Me}_{3} \mathrm{SiSiPh}_{3}$ & 3000 & 1.10 & 56 \\
4 & $\mathrm{Ph}_{3} \mathrm{SiSiPh}_{3}$ & 2600 & 1.08 & 59 \\
\hline
\end{tabular}

${ }^{a}$ The electroreduction was carried out by using Mg electrodes, and the ultrasound $(47 \mathrm{kHz})$ was applied during the reaction. The anode and cathode were alternated with the interval of $15 \mathrm{sec}$. [Dichlorosilane $3 \mathrm{a}]=0.50 \mathrm{~mol} / \mathrm{L} ;[\mathrm{LiClO} 4]$ $=0.35 \mathrm{~mol} / \mathrm{L}$; supplied electricity, $4 \mathrm{~F} / \mathrm{mol} .{ }^{b}$ The disilane additives were prepared in situ by electroreductive coupoling of the corresponding chlorosilanes before electroreductive polymerization of 3a. Total concentration of chlorosilanes

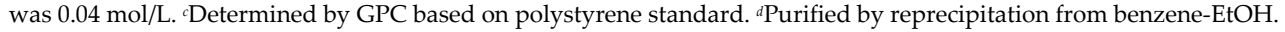

Table 9. Electroreductive polymerizartion of dichlomethylphenylsilane (3a) in the presence of disilane additives $^{a}$

triphenylsilyl group terminated polysilane. The resulting polysilane is isolable but does not lose its polymerizability completely since the triphenylsilyl group at the terminal position acts as an activator, that is, it probably reacts as a macroinitiator.

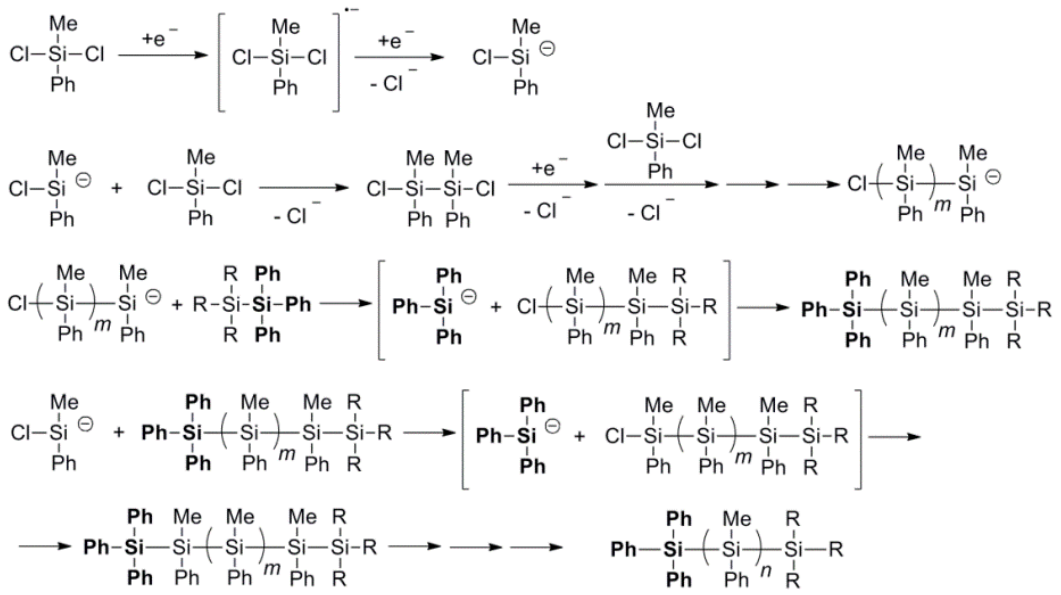

Scheme 19. 


\section{Electroreductive block copolymerization using triphenylsilyl group- terminated polysilane [32]}

The triphenylsilyl group terminated polysilanes have been synthesized by the electroreductive polymerization of dichloromethylphenylsilane (3a) in the presence of the electroreductively prepared disilane additives 2 . The electroreductive termination with chlorotriphenylsilane (1d) was carried out to ensure the terminus of the resulting polysilane for triphenylsilyl group. The polysilanes were obtained as white powders in $15-32 \%$ yields after reprecipitation from benzene-ethanol, and the number average molecular weights were estimated by GPC to be 3000-3740 (Table 10). By using the isolated triphenylsilyl groupterminated poly(methylphenylsilane) $\mathbf{1 3}$ as a macroinitiator, the electroreductive polymerization of dibutyldichlorosilane (3h) was carried out (Scheme 20, Table 10). Under these conditions dichlorsilane $3 \mathbf{h}$ was first electroreduced to form the corresponding oligomeric silyl anion. Electroreductive copolymerization was found to proceed by the attack of the oligomeric silyl anion to triphenylsilyl group-terminated polysilane $\mathbf{1 3}$ and further electroreductive condensation with dichlorosilane $\mathbf{3 h}$ affording the corresponding copolymer, polymethylphenylsilane-block-polydibutylsilane (21), in 16-38\% yields depending on the disilane additives (entries 1-3). The molecular weight of the copolymer obtained from the polysilane $13(M n=3350)$ was 4730 (entry 3$)$. The GPC profiles of the resulting copolymers 21 were monomodal and the polydispersity index values $(\mathrm{Mw} / \mathrm{Mn})$ were 1.2-1.4. The repeat unit ratio (-Si(Me)Ph- : -SiBu2-) of the resulting copolymer 21 (entry 3) was $75: 25$, which showed a good agreement with the calculated ratio $(74: 26)$.

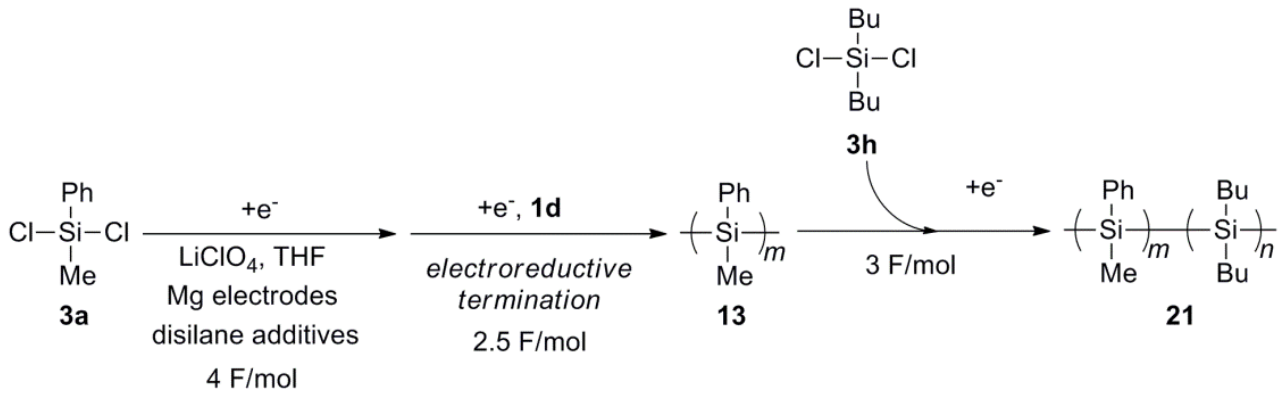

Scheme 20.

Polydibutylsilane-block-polymethylphenylsilane $\left(\mathbf{2 1}^{\prime}\right)$ was also obtained by using triphenylsilyl group-terminated polydibutylsilane (22) as a macroinitiator (Scheme 21). The electroreductive polymerization of dibutyldichlorosilane $(3 \mathbf{h})$ in the presence of the disilane $\mathbf{2 d}$ followed by electroreductive termination with chlorotriphenylsilane (1d) afforded the macroinitiator $22(\mathrm{Mn}=3950, \mathrm{Mw} / \mathrm{Mn}=1.7)$. The electroreductive polymerization of dichloromethylphenylsilane (3a) was found to initiate from 22 producing the corresponding copolymer 21' in $25 \%$ yield, and the molecular weight of 21' was 4390 (Scheme 21). The polydispersity index values $(\mathrm{Mw} / \mathrm{Mn})$ was 1.3 , and the repeat unit ratio (-SiBu2- : $-\mathrm{Si}(\mathrm{Me}) \mathrm{Ph}-)$ was $61: 39$. 


\begin{tabular}{|c|c|c|c|c|c|c|c|c|}
\hline \multirow{3}{*}{ entry } & \multicolumn{3}{|c|}{$\begin{array}{l}\text { preparation of } \\
\text { the macroinitiator } 13^{a}\end{array}$} & \multicolumn{5}{|c|}{$\begin{array}{l}\text { polymethylphenylsilane-block-polydibutylsilane } \\
\qquad(\mathbf{2 1})^{b}\end{array}$} \\
\hline & \multirow{2}{*}{$\begin{array}{c}\text { disilane } \\
\text { additives }\end{array}$} & \multirow{2}{*}{$M n^{c}$} & \multirow{2}{*}{$M \mathrm{w} / \mathrm{Mn}^{c}$} & \multirow{2}{*}{$M n^{c}$} & \multirow{2}{*}{$M \mathrm{w} / \mathrm{Mn}^{c}$} & \multicolumn{2}{|c|}{$m: n$} & \multirow{2}{*}{ yield, $\%^{f}$} \\
\hline & & & & & & observed $^{d}$ & calculated $^{e}$ & \\
\hline 1 & $\mathrm{Me}_{3} \mathrm{SiSiMe}_{3}$ & 3740 & 1.9 & 5530 & 1.4 & $83: 17$ & $70: 30$ & 16 \\
\hline 2 & $\mathrm{Me}_{3} \mathrm{SiSiPh}_{3}$ & 3000 & 1.3 & 4080 & 1.4 & $66: 34$ & $77: 23$ & 28 \\
\hline 3 & $\mathrm{Ph}_{3} \mathrm{SiSiPh}_{3}$ & 3350 & 1.4 & 4730 & 1.2 & $75: 25$ & $74: 26$ & 38 \\
\hline
\end{tabular}

${ }^{a}$ The reaction conditions of the preparation of the macroinitiator $\mathbf{1 3}$ are as follows: The electroreduction was carried out by using magnesium electrodes under sonication $(50 \mathrm{kHz})$ and the polarity of the electrodes was alternated with an interval of $15 \mathrm{sec}$. The concentration of 3a was $0.67 \mathrm{~mol} / \mathrm{L}$. Polymerization was terminated by electroreduction with triphenylchlorosilane (1d) ( $0.5 \mathrm{~mol} \%$ of 3a). ${ }^{b}$ Electroreductive copolymerization was carried out without disilane additives. ${ }^{c}$ Determined by GPC based on polystyrene standard. ${ }^{d}$ Determined by ${ }^{1} \mathrm{H}$ NMR. ${ }^{e}$ Calculated from the observed molecular weight of the copolymer $\mathbf{2 1}$ as the assumption that the molecular weight of the macroinitiator $\mathbf{1 3}$ was not changed. $f$ Purified by reprecipitation from benzene-ethanol.

Table 10. Electroreductive block copolymerization with dibutyldichlorosilane ( $3 \mathbf{h})$ using triphenylsilyl group-terminated poly(methylphenylsilane) (13) as a macroinitiator

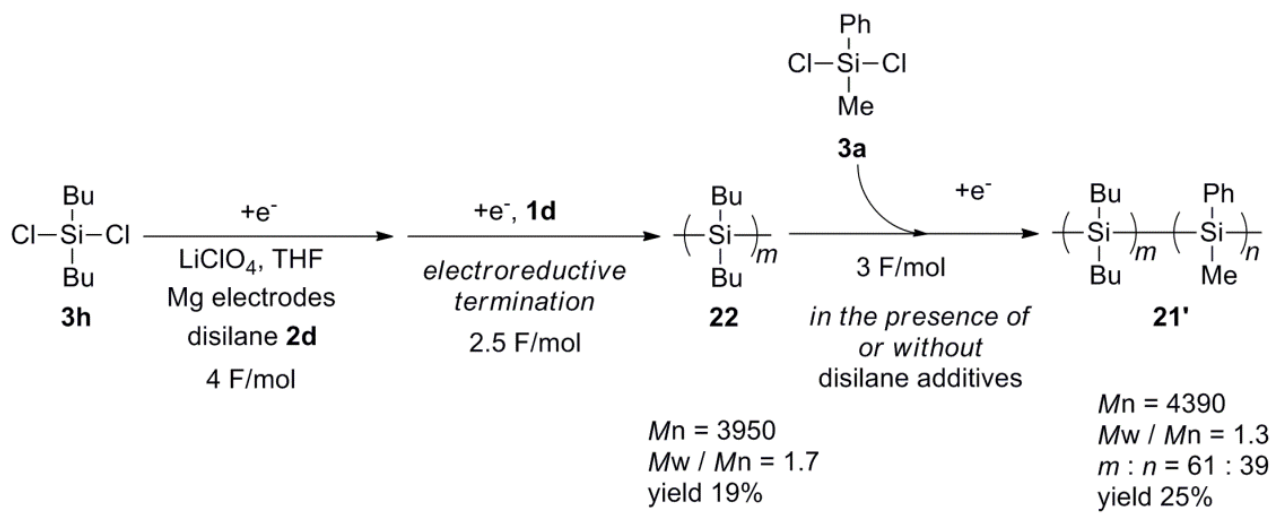

Scheme 21.

The UV absorption spectra of the resulting polysilane 21 (entry 3, Table 10) was compared with those of poly(methylphenylsilane) $(M n=3350, M w / M n=1.4)$, poly(dibutylsilane) ( $M n$ $=3950, \mathrm{Mw} / \mathrm{Mn}=1.7)$, and poly(methylphenylsilane-co-dibutylsilane) (random copolymer) (Figure). Poly(methylphenylsilane) showed a $\pi-\pi^{*}$ band at $271 \mathrm{~nm}(\varepsilon \max =4831)$ and a $\sigma-\sigma^{*}$ band at $326 \mathrm{~nm}\left(\varepsilon_{\max }=4766\right)$ at $4^{\circ} \mathrm{C}$ (Figure (a)). Poly(methylphenylsilane) $(M \mathrm{w}=9000)$ prepared by Wurtz coupling under sonication was reported to show a $\sigma-\sigma^{*}$ band at $332 \mathrm{~nm}$ $(\varepsilon \max =4100)$ [33]. The $\lambda \max$ value of the electroreductively prepared poly(methyphenylsilane) was a little shorter and it is probably due to relatively lower molecular weight. In fact Wurtz coupling-synthesized poly(methylphenylsilane) having 5000 of $\mathrm{Mw}$ showed a $\sigma-\sigma^{*}$ band at $328 \mathrm{~nm}$ [34]. Poly(dibutylsilane) showed only a $\sigma-\sigma^{*}$ band at $309 \mathrm{~nm}$, and the $\varepsilon_{\max }$ value (9611) was two times higher than that of poly(methylphenylsilane) (Figure (b)). The UV absorption spectrum of the helical form of poly(di- $n$-alkylsilane)s is typically centered near $315 \mathrm{~nm}$, while the more planar 
conformation is typically centered at $375 \mathrm{~nm}[35,36]$. Poly(dibutylsilane) obtained in this study showed the $\lambda$ max value corresponding to helical backbone conformation. The $\varepsilon_{\max }$ of the $\sigma-\sigma^{*}$ band of poly(methylphenylsilane) was observed to decrease with an increase in temperature [5]. The UV spectra of copolymer 5 showed a $\pi-\pi^{*}$ band at $273 \mathrm{~nm}(\varepsilon \max =2723)$ and a $\sigma-\sigma^{*}$ band at $306 \mathrm{~nm}\left(\varepsilon_{\max }=2949\right)$ (Figure $\left.(\mathbf{d})\right)$, while the random copolymer showed a $\pi-\pi^{*}$ band at $272 \mathrm{~nm}\left(\varepsilon_{\max }=2438\right)$ and a $\sigma-\sigma^{*}$ band at $309 \mathrm{~nm}\left(\varepsilon_{\max }=2065\right)$ (Figure (c)). The $\varepsilon$ max value of the $\sigma-\sigma^{*}$ band of copolymer 21 was higher than that of the random copolymer, and less temperature dependence of $\varepsilon \max$ was observed in the spectrum of copolymer 21 . These results indicate that copolymer $\mathbf{2 1}$ has long sequences of dibutylsilylene units, that is, block structure.
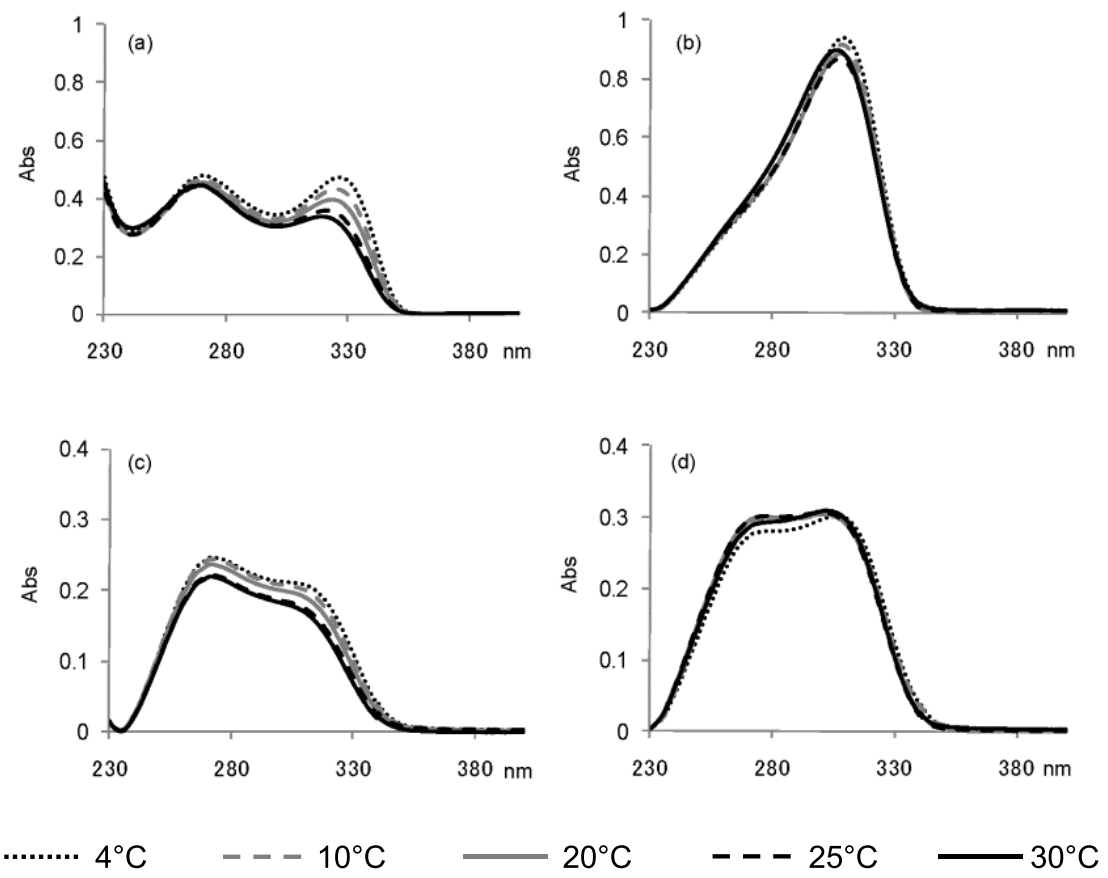

Figure 1. UV absorption spectra of (a) poly(methylphenylsilane) $(\mathrm{Mn}=3350, \mathrm{Mw} / \mathrm{Mn}=1.4)$, (b) poly (dibutylsilane) $(M n=3950, M w / M n=1.7)$, (c) poly(methylphenylsilane-co-dibutylsilane) $(M n=$ 4340, $\mathrm{Mw} / \mathrm{Mn}=1.5,-\mathrm{Si}(\mathrm{Me}) \mathrm{Ph}-:-\mathrm{SiBu}_{2}=67: 33$ ), and (d) poly(methylphenylsilane)-blockpoly (dibutylsilane) $\left(M n=4080, M w / M n=1.4,-S i(M e) P h-:-S_{B B u}-=66: 34\right)$ in THF at $0,10,20,25$, and $30^{\circ} \mathrm{C}$.

\section{Conclusion}

The formation of Si-Si bonds was achievable by the electroreductive condensation of organochlorosilanes with Mg sacrificial electrode. Disilanes, trisilanes, and tetrasilanes were readily obtained in good to moderate yield. Moreover, this method was also remarkably effective to the synthesis of polysilanes. The molecular weight and yield of the polymers 
was controlled by the concentration of monomers and the supplied electricity. The mildness of the reaction conditions allowed to use a wide variety of monomers, and enabled the synthesis of the functionalized polysilanes and the structure-controlled polysilanes. The electroreductive polymerization of the dichlorooligosilanes was highly useful for the synthesis of sequence-ordered polysilanes. Moreover, this electroreductive method also provided a new procedure to synthesize well-controlled di-block polysilane copolymers. Since the present electroreductive polymerization requires only a single compartment cell, it is undoubtedly one of the simplest and most powerful tools for synthesis of polysilanes.

\section{Author details}

Manabu Ishifune

Department of Applied Chemistry, Faculty of Science and Engeneering,

Kinki University, Higashi-Osaka, Osaka, Japan

\section{References}

[1] West R (1986) The polysilane high polymers. J. Organomet. Chem. 300(1-2): 327-346.

[2] Yajima S, Hasegawa Y, Hayashi J, Iimura M (1978) Synthesis of continuous silicon carbide fiber with high tensile strength and high Young's modulus. Part 1. Synthesis of polycarbosilane as precursor. J. Mater. Sci. 13(12): 2569-2576.

[3] Hasegawa Y, Okamura K (1985) Silicon carbide-carbon composite materials synthesized by pyrolysis of polycarbosilane. J. Mater. Sci. Lett. 4(3): 356-8.

[4] Miller RD, Willson CG, Wallroff GM, Clecak N, Sooriyakumaran R, Michl J, Karatsu T, McKinley AJ, Klingensmith KA, Downing J (1989) Polysilanes: photochemistry and deep-UV lithography. Polym Eng Sci 29(13): 882-886

[5] Miller RD, Michl J (1989) Polysilane high polymers. Chem. Rev. 89(6): 1359-1410.

[6] West R, David LD, Djurovich PI, Stearley KL, Srinivasan KSV, Yu H (1981) Phenylmethylpolysilanes: formable silane copolymers with potential semiconducting properties. J. Am. Chem. Soc. 103(24): 7352-7354.

[7] Kepler RG, Zeigler JM, Harrah LA, Kurtz SR (1987) Photocarrier generation and transport in $\sigma$-bonded polysilanes. Phys. Rev. B 35(6): 2818-2822.

[8] Baumert JC, Bjorklund GC, Jundt DH, Jurich MC, Looser H, Miller RD, Rabolt J, Soorijakumaran R, Swalen JD, Twing RJ (1988) Temperature dependence of the thirdorder nonlinear optical susceptibilities in polysilanes and polygermanes. Appl. Phys. Lett. 53(13): 1147-1149.

[9] Matyjaszewski K, Greszta D, Hrkach JS, Kim HK (1995) Sonochemical synthesis of polysilylenes by reductive coupling of disubstituted dichlorosilanes with alkali metals. Macromolecules 28(1): 59-72.

[10] Jones RD, Holder SJ (2006) High-yield controlled syntheses of polysilanes by the Wurtztype reductive coupling reaction. Polym. Int. 55(7): 711-718.

[11] Koe J (2008) Contemporary polysilane synthesis and functionalisation. Polym. Int. 58(3): 255-260. 
[12] Tilley TD (1993) The coordination polymerization of silanes to polysilanes by a " $\sigma$-bond metathesis" mechanism. Implications for linear chain growth. Acc. Chem. Res. 26(1): 2229.

[13] Minato M, Matsumoto T, Ichikawa M, Ito T (2003) Dehydropolymerization of arylsilanes catalyzed by a novel silylmolybdenum complex. Chem. Commun. (24): 2968-2969.

[14] Sanji T, Kawabata K, Sakurai H (2000) Alkoxide initiation of anionic polymerization of masked disilenes to polysilanes. J. Organomet. Chem. 611(1-2): 32-35.

[15] Sanji T, Isozaki S, Yoshida M, Sakamoto K, Sakurai H (2003) Functional transformation of poly(dialkylaminotrimethyldisilene) prepared by anionic polymeriztion of the masked disilenes. The preparation of a true polysilastyrene. J. Organomet. Chem. 685 (1-2): 65-69.

[16] Cypryk M, Gupta Y, Matyjaszewski K (1991) Anionic ring-opening polymerization of 1,2,3,4-tetramethyl-1,2,3,4-tetraphenylcyclotetrasilane. J. Am. Chem. Soc. 113(3): 1046-7.

[17] Suzuki M, Kotani J, Gyobu S, Kaneko T, Saegusa T (1994) Synthesis of sequence-ordered polysilane by anionic ring-opening polymerization of phenylnonamethylcyclopentasilane. Macromolecules 27(8): 2360-2363.

[18] Hengge E, Litscher, G (1976) A new electrochemical method for the formation of siliconsilicon bonds. Angew] Chem] 88(12): 414.

[19] Hengge E, Litscher G (1978) Electrochemical formation of di-, oligo- and polysilanes. Monatsh. Chem. 109(5): 1217-1225.

[20] Hengge E, Firgo H (1981) An electrochemical method for the synthesis of silicon-silicon bonds. J. Organomet. Chem. 212(2): 155-161.

[21] Shono T, Kashimura S, Ishifune M, Nishida R (1990) Electroreductive formation of polysilanes. J. Chem. Soc. Chem. Commun. (17): 1160-1161.

[22] Kashimura S, Ishifune M, Yamashita N, Bu HB, Takebayashi M, Kitajima S, Yoshihara D, Kataoka Y, Nishida R, Kawasaki S, Murase H, Shono T (1999) Electroreductive synthesis of polysilanes, polygermanes, and related polymers with magnesium electrodes. J. Org. Chem. 64(18): 6615-6621.

[23] Ishifune M, Kashimura S, Kogai Y, Fukuhara Y, Kato T, Bu HB, Yamashita N, Murai Y, Murase H, Nishida R (2000) Electroreductive synthesis of oligosilanes and polysilanes with ordered sequences. J. Organomet. Chem. 611(1-2): 26-31.

[24] Umezawa M, Takeda M, Ichikawa H, Ishikawa T, Koizumi T, Nonaka, T (1991) Electroreductive polymerization of mixtures of chloromonosilanes. Electrochim. Acta 36(3-4): 621-624.

[25] Biran C, Bordeau M, Pons P, Leger MP, Dunogues J (1990) Electrosynthesis, a convenient route to di- and polysilanes. J. Organomet. Chem. 382 (3): C17-C20.

[26] Kunai A, Kawakami T, Toyoda E, Ishikawa M (1991) Electrochemistry of organosilicon compounds. 2. Synthesis of polysilane oligomers by a copper electrode system. Organometallics 10(6): 2001-2003.

[27] Okano M, Takeda K, Toriumi T, Hamano H (1998) Electrochemical synthesis of polygermanes. Electrochim. Acta 44(4): 659-666. 
[28] Yamada K, Okano M (2006) Electrochemical synthesis of poly(cyclotetramethylenesilylene) Electrochemistry 74(8): 668-671.

[29] Kashimura S, Ishifune M, Bu HB, Takebayashi M, Kitajima S, Yoshihara D, Nishida R, Kawasaki S, Murase H, Shono T (1997) Electroorganic chemistry. 153. Electroreductive synthesis of some functionalized polysilanes and related polymers. Tetrahedron Lett. 38(26): 4607-4610.

[30] Ishifune M, Kogai Y, Uchida K (2005) Effect of disilane additives on the electroreductive polymerization of organodichlorosilanes. J. Macromol. Sci. Part A Pure and Appl. Chem. 42(7): 921-929.

[31] Chen SM, David LD, Haller KJ, Wadsworth CL, West R (1983) Isomers of (PhMeSi)6 and (PhMeSi) 5 Organometallics 2(3): 409-414.

[32] Ishifune M, Sana C, Ando M, Tsuyama Y (2011) Electroreductive block copolymerization of dichlorosilanes in the presence of disilane additives. Polym. Int. 60(8): 1208-1214.

[33] Terunuma D, Nagumo K, Kamata N, Matsuoka K, Kuzuhara H (2000) Preparation and characterization of water-soluble polysilanes bearing chiral pendant ammonium moieties. Polymer Journal 32: 113-117.

[34] Herzog U, West R (1999) Hererosubstituted polysilanes. Macromolecules 32: 2210-2214.

[35] Hu Z, Zhang F, Huang H, Zhang M, He T (2004) Morphology and structure of poly(di$n$-butylsilane) single crystals prepared by controlling kinetic process of solvent evaporation. Macromolecules 37: 3310-3318.

[36] Chunwachirasiri W, Kanaglekar I, Winokur MJ, Koe JC, West R (2001) Structure and chain conformation in poly(methyl-n-alkyl)silanes. Macromolecules 34: 6719-6726. 